\section{HSE}

Historia Social y de la Educación

Social and Education History
Hipatia Press

www.hipatiapress.com

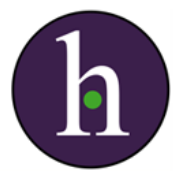

Instructions for authors, subscriptions and further details:

http://hse.hipatiapress.com

\title{
Class in contemporary China
}

Antonio Fernández-Jiménez ${ }^{1}$

1) Universidad de Granada (España)

Date of publication: June $23^{\text {rd }}, 2017$

Edition period: Edition period: June 2017-October 2017

To cite this article: Fernández-Jiménez, A. (2017). Class in Contemporary China [Review of the book]. Social and Education History 6(2), 220-222. doi: 10.17583/hse.2017.2485

To link this article: http://dx.doi.org/10.17583/hse.2017.2485

\section{PLEASE SCROLL DOWN FOR ARTICLE}

The terms and conditions of use are related to the Open Journal System and to Creative Commons Attribution License (CC-BY). 


\section{Reviews (I)}

Goodman, D. S. G. (2014). Class in Contemporary China. Cambridge: Polity Press.

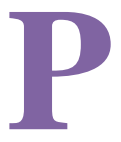

ara el mundo Occidental, China continúa siendo un entorno que guarda secretos sobre su estructura social y económica. Por ello, este libro aporta una comprensión sobre estos aspectos, así como del significado y las razones de la importancia de las clases en China. A través de siete capítulos, su autor presenta una clara radiografía de la China actual, aportando información y datos para un mejor entendimiento sobre las clases y su evolución, desde el comienzo de la dictadura de Mao Zedong en 1949 hasta nuestros días. La Reforma de 1976 supuso un intento de establecer un sistema parecido al capitalismo, quedando una economía de mercado socialista que ha generado desigualdad y un aumento de la estratificación social. Con una amplia bibliografía, Goodman muestra, en los dos primeros capítulos, los cambios que ha sufrido China durante esa nueva etapa, como por ejemplo, un menor control por parte del gobierno en la gestión económica. Esto supuso una economía más abierta a las interacciones con el resto de países del mundo, así como regulaciones legislativas que reconocieron la propiedad privada y sus derechos. Un proceso comúnmente conocido como "privatización", pero que en China se ha producido por la introducción de fuerzas del mercado en la gestión de la economía y en el ámbito empresarial y no por una venta a gran escala, como ha ocurrido en otras reformas de sistemas socialistas, de tal manera que se ha creado una economía caracterizada por empresas híbridas entre lo público y lo privado.

2017 Hipatia Press

ISSN: 2014-3567

DOI: $10.17583 /$ hse.2017.2485

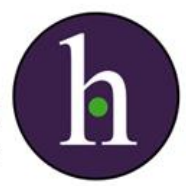


En los siguientes capítulos se analizan las diferentes clases sociales que existen hoy en día en China, como son la clase dominante (la única que no aparece en plural, pues sus integrantes comparten similitudes y fuertes lazos con el Partido del Estado), las clases medias y las clases subordinadas; destacando una clase media que posee elementos más propios de la clase superior o dominante. Por lo tanto, la clase media parece ser más un discurso que una verdadera estratificación social, siendo difícil de identificar dentro de la República Popular de China (RPC), ya que se trata de un grupo fragmentado y heterogéneo formado por una variedad de emprendedores, profesionales y gestores, que participan en las instituciones formales de la vida política, teniendo así más probabilidad para obtener préstamos y financiación. Esta nueva élite política y económica tiene tal influencia que bloquea el camino hacia un cambio de régimen o democratización.

El último capítulo del libro está dedicado a exponer una serie de conclusiones que aportan al lector una visión general y completa del entramado social de China en la actualidad, haciendo especial mención a las clases trabajadoras por su potencial, pues la ideología de la RPC les da autoridad y legitimidad y, además, tienen un alto impacto sobre el régimen por cómo interactúan con las élites. Goodman también resume ideas claves que vienen a decir que el conflicto de las clases en este país asiático es silenciado, limitándose la expresión pública sobre este asunto. Un país en el que, frecuentemente, el estatus social y la cultura son equiparables; dónde los campesinos que emigraron a la ciudad y ahora son trabajadores "corrientes" tienen un estatus social más bajo y carecen de cultura, siendo considerados como inferiores por los trabajadores residentes en las ciudades. Son trabajadores que tienen una autopercepción de "condenados" por haber nacido en el entorno rural. Por tanto, el autor muestra que no sólo hay desigualdad en la cultura, sino que se produce también una cultura de la desigualdad, a lo que se suma la situación de descontento que existe, entre la sociedad en general, debido a la corrupción y otras irregularidades por parte de las instituciones de poder.

En definitiva, se trata de una obra de consulta necesaria para investigadores y personas interesadas en conocer la estratificación social de la China contemporánea. De igual manera, también ofrece la oportunidad de 
222 Fernández-Jiménez - Class in Contemporary China [Review]

profundizar, desde diferentes perspectivas, en el sistema de clases sociales y, por ende, económicas que ha desarrollado China en las últimas décadas y que ha generado el sentimiento de deseo por un cambio, que aunque no será el <<gran cambio>>, sí que es el anhelado por la verdadera clase trabajadora, consciente de que el Partido del Estado está alejado de ella, pero sí más ligado a las clases medias.

Antonio Fernández Jiménez

Universidad de Granada antoniferjim@ugr.es 